\title{
Memory of Chiral Molecules Define Their Interactions and the Results of Resolution Processes
}

\author{
Emese Pálovics*, Elemér Fogassy \\ Department of Organic Chemistry and Technology, Budapest University of Technology and Economics, Budapest, Hungary
}

Email address:

epalo@mail.bme.hu (E. Pálovics), efogassy@mail.bme.hu (E. Fogassy)

${ }^{*}$ Corresponding author

To cite this article:

Emese Pálovics, Elemér Fogassy. Memory of Chiral Molecules Define Their Interactions and the Results of Resolution Processes. American Journal of Chemical Engineering. Vol. 6, No. 4, 2018, pp. 65-71. doi: 10.11648/j.ajche.20180604.15

Received: May 15, 2018; Accepted: August 10, 2018; Published: September 21, 2018

\begin{abstract}
The preparation of pure enantiomers has an increasing demand both for academic and industrial (pharmaceutical) practice. This is not surprising, because the active ingredients of a main part of medicines (about 70-80\%) are pure enantiomers. Several selective methods are known for preparation of pure enantiomers but the more economical and usual method is the resolution, when the pure enantiomers are obtained from diastereomeric salts formed due the reaction of the racemic compound and resolving agent in adequate conditions (solvent, temperature crystallization time). Since the first resolution effectuated by Pasteur the researchers have tried to explain what is happening during resolution, but this has not yet been fully accomplished, it is still a mystery. In this paper is described our proposal for resolution's mechanism, based on systematization of our results and observations made during the resolution, taking into consideration the principal characteristics of enantiomeric mixtures, namely the eutectic composition and their helicity. We suppose that the enantiomers have a memory and they used it during the resolution processes, tending to form their stable symmetric conformation.
\end{abstract}

Keywords: Resolution, Enantiomers, Diastereomers, Eutectic composition, Homo- and Heterochiral Associates, Helical Structure

\section{Introduction}

Based on our previous experiments and knowledge, our goal was to deduce the distribution of diastereomeric salts formed by chiral-chiral interactions - between solid and liquid phases, from the determinant role of racemic compounds' properties and that of the resolving agents'. Our attention was first drawn by the defining roles of the eutectic composition $\left(\mathrm{ee}_{\mathrm{Eu}}\right)$ of the enantiomeric mixtures and the formation of their conformers. We have to presume that the chiral molecules remember with their structures, and they apply it in their reactions.

\section{The Memory-Based Reproduction of Conformers's Ratio}

The ratio of major and minor conformers of the racemic
Grandaxin (GRA) in chloroform occurs instantaneously [1] (kinetic control) (Figure 1a.), while in the case of pure enantiomers, the same ratio appears only after 48 hours (thermodynamic control) [2] (Figure 1b.). From this we can conclude presumably, that the enantiomer remembers the ratio of its conformers in the presence of the other enantiomer (its mirror-image pair). However, the memorybased reproduction takes time (thermodynamic control), while the stabilization of equilibrium is instantaneous (kinetic control) in the presence of another chiral molecule (in the given case the other enantiomer). Moreover, in the course of the interaction of the molecules the code is prevailed and they vindicate their memories even against each other, as the similar compounds do not hinder but help one another in the formation of the conformer ratio. 


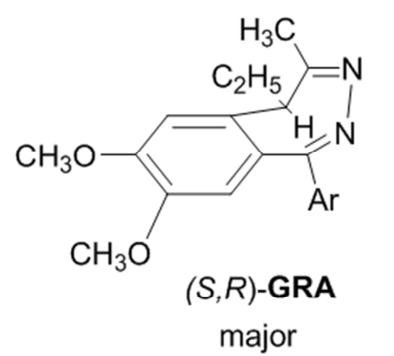

major

$78 \%$

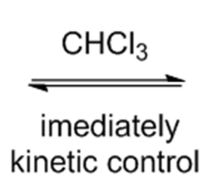

Conformers

$\mathrm{CHCl}_{3}$

(S)-GRA

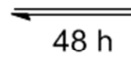

thermodynamic

major

$78 \%$

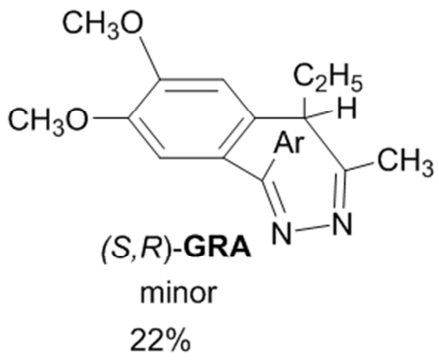

a.

b.

The ratio of major and minor conformers is stabilized conform enantiomer's memory

Figure 1. The stabilization of the conformers' ratio in the racemic grandaxin (GRA) (a.) and GRA enantiomers (b.) respectively.

\section{Behaviour of the Enantiomeric Mixtures}

As the eutectic composition on the binary melting phase diagram $\left(\mathrm{ee}_{\mathrm{Eu}}: 88 \%\right)$ of the enantiomeric mixture of the racemic grandaxin is determined by four different structures, the binary phase diagram of the major or minor conformers are unknown. Presumably the eutectic composition is mainly determined by the composition of the major conformer.

The behaviour of the mixtures of chiral compounds can be deduced from the behaviour of the enantiomeric mixtures [3]. Obviously the diastereomeric mixtures, formed by the reaction of enantiomeric mixtures, show the same non-linear behaviour, as they follow the behaviour of the enantiomeric mixtures.

This behaviour of enantiomeric mixtures can be observed even on the melting binary phase diagram (Figure 2), by plotting the melting temperature of the different enantiomeric mixtures in function of their composition, but the correlation
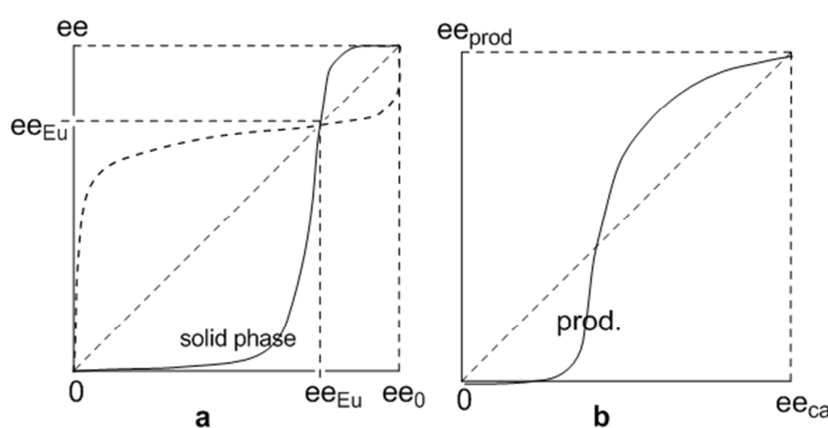

is not linear. The distribution of enantiomeric mixtures between two phases are different, except for the eutectic composition [4] (where the composition is the same in both phases). Above the eutectic compositions, the enantiomeric mixtures can be found in molten phase, while below they are in solid phase. The eutectic composition $\left(\mathrm{ee}_{\mathrm{Eu}}\right)$ is a characteristic property (substantial and chemical) of the behaviour of given enantiomeric mixtures.

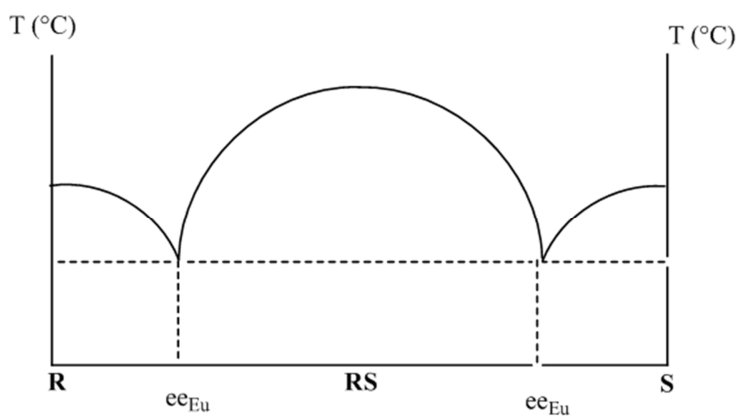

Figure 2. Binary melting phase diagram.
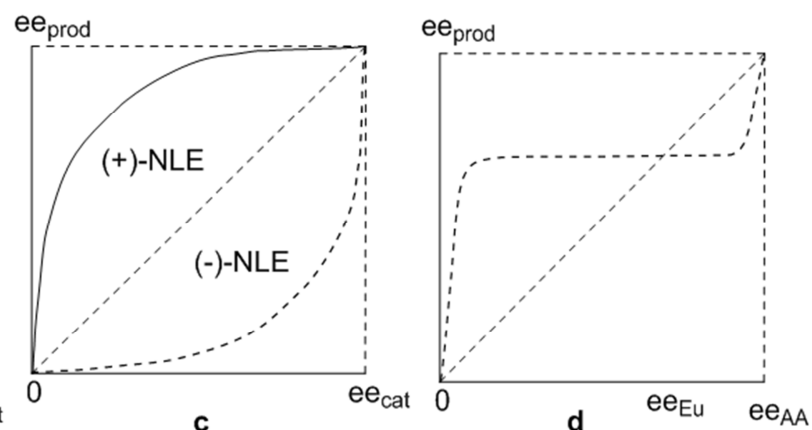

Figure 3. Distribution between the phases of any enantiomeric mixture reaction, plotted in the function of the starting enantiomeric mixtures composition (ee ${ }_{0}$ ee). In case of a) recrystallization; b) and c) chiral metal complex catalysts; d) organocatalysis. 
The non-linear behaviour can be observed not only in case of the recrystallization (Scheme 3 a.), but also when complex chiral metal catalysts are applied, if the enantiomeric ratio of the products is plotted against the ratio of the ligands (Figure 3 b., c.) $[5,6]$. The same non-linear behaviour (NLE) can be observed applying enantiomeric mixtures of amino acids as organocatalysts in aldol reactions. By plotting the enantiomeric ratio of the product in function of the enantiomer ratio of the catalyst'enantiomeric mixture, the first one practically equals to the eutectic ratio of the catalyst's enantiomeric mixtures, although the enantiomer compositions differed significantly. The purity of the product equals to the value of the eutectic composition of the catalyst $\left(\mathrm{ee}_{\mathrm{EuCat}} \sim \mathrm{ee}_{\text {product }}\right)$ (Figure 3d.) [7,8].

\section{Role of the Solvent}

Beside the effect of the eutectic composition, the role of the applied solvent can also be observed. For example, in case of the resolution of the intermediate of Flumequine (FTHQ) with di- $p$-toluyl- $(R, R)$-tartaric acid (DPTA), the composition of the precipitated diastereomer could be influenced by the modification of the solvent. At the same time in both presented solvents the enantiomer ratio of the FTHQ enantiomer, separated from its DPTA-salt, correspond well to the eutectic composition of the FTHQ enantiomeric mixture (ee $\mathrm{EuFTHQ}_{\text {D }} \sim \mathrm{ee}_{\mathrm{Dia}}$ ) (Figure 4) [9].

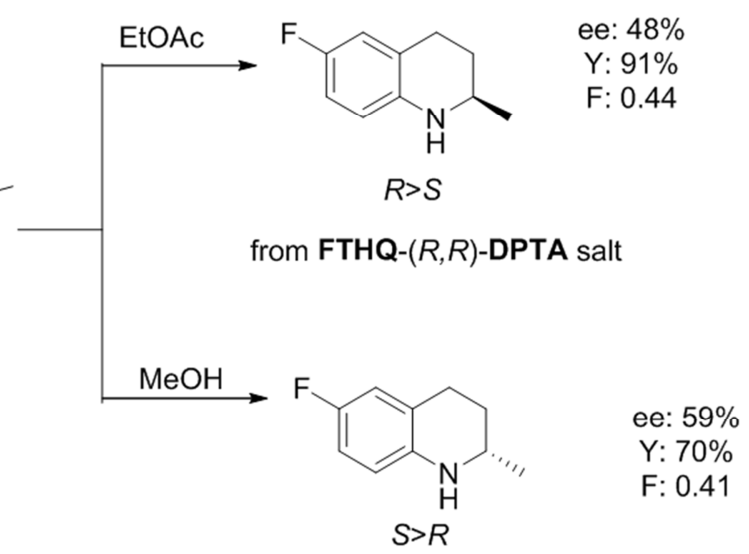

from FTHQ-(R,R)-DPTA salt

Figure 4. The composition of the diasteromer can be influenced, predetermined by the variation of the solvent.

\section{Role of Crystallization Time}

In case of the present resolution, the effect of time could also be observed. Although, by prolonging the crystallization time, the composition of the precipitated diastereomer changed, in both cases of kinetic and thermodynamic control, the eutectic composition of the racemic compound (ee $\left.e_{\text {EuRac }}\right)$ is determinant in the formation of the stoichiometry of the diastereomer (Figure 5) [9]. Thus the eutectic composition of the racemic compound participates in the formation of the diastereomer salt $\left(\mathrm{ee}_{\mathrm{EuRac}} \sim \mathrm{ee}_{\mathrm{Dia}}\right)$.

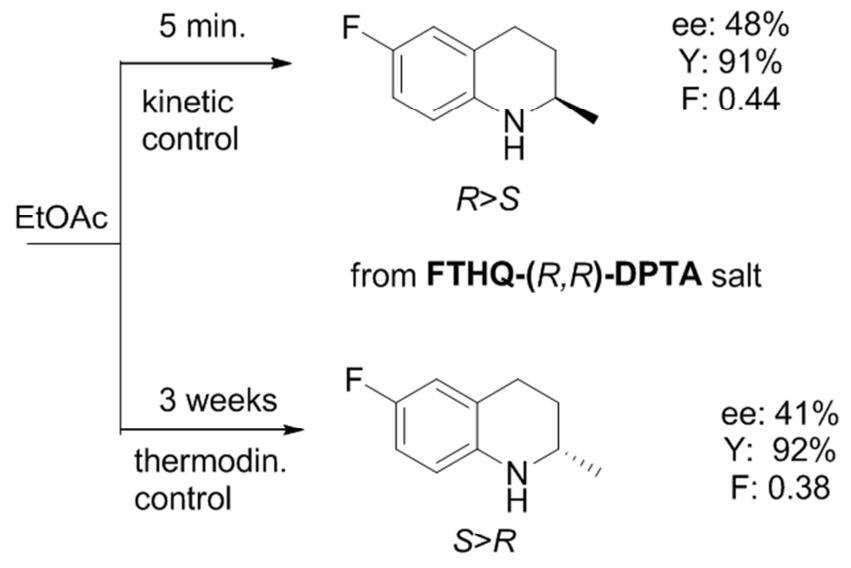

from FTHQ-(R,R)-DPTA salt

Figure 5. The enantiomer mixture, taking part in the formation of the diastereomer present in the crystalline phase, alters in the function of the crystallization time. 


\section{Effect of the Eutectic Composition, the Helicity of Supramolecular Associations}

In order to determine the influence of the eutectic composition of the racemic compound on the formation of the diastereomers, the average of the results of 45 different resolutions, where the racemic compounds were resolved with different resolving agents, was studied $[10,11,12]$. The average of enantiomeric excess values of the enantiomers separated from the diastereomers $\left(\mathrm{ee}_{\mathrm{Dia}}\right)$ is $75 \%$, while the average ee value of the eutectic compositions of the racemic compounds (ee $\mathrm{EuRac}_{\mathrm{E}}$ ) is $73,2 \%$, consequently in all cases $\mathrm{ee}_{\text {EuRac }} \sim \mathrm{ee}_{\text {Dia }}($ Table 1$)$.

Table 1. Correlation between the average ee $e_{\text {Dia }}$ data of the investigated resolutions and the average value of ee $e_{\text {Rac }}$.

\begin{tabular}{llll}
\hline $\begin{array}{l}\text { Number of } \\
\text { resolutions }\end{array}$ & $\begin{array}{l}\text { ee }_{\text {eu Rac }} \\
\text { (average)\% }\end{array}$ & $\begin{array}{l}\text { ee }_{\text {euDia }} \\
\text { (average)\% }\end{array}$ & F (average) \\
\hline 45 & 73 & 75 & 0.56 \\
\hline
\end{tabular}

Among of these examples some resolutions were carried out using structurally related resolving agents of the same molecular structure as the racemic compound (e.g. derivatives of amino acids) $[10,11,12]$. In these cases the diastereomers can be considered as quasi enantiomeric mixtures, $\mathrm{ee}_{\mathrm{EuRac}} \sim \mathrm{ee}_{\text {Dia }}$.

The eutectic compositions of resolving agents were also averaged (29 experiments) ( $e_{\text {Res average }}: 78 \%$ ), as well as the enantiomeric purities of the enantiomers received from the formed diastereomers (ee $e_{\text {Dia average }}: 80 \%$ ) (Table 2).

Table 2. Correlation between the average ee Dia data of the investigated resolutions and the average value of ee $e_{\text {Res. }}$.

\begin{tabular}{llll}
\hline $\begin{array}{l}\text { Number of } \\
\text { resolutions }\end{array}$ & $\begin{array}{l}\text { ee }_{\text {euRes }} \\
\text { (average) } \%\end{array}$ & $\begin{array}{l}\text { ee }_{\text {euDia }} \\
\text { (average) } \%\end{array}$ & F (average) \\
\hline 29 & 78 & 80 & 0.54 \\
\hline
\end{tabular}

From the results it can be stated that the enantiomeric purity of the diastereomers is influenced by the eutectic composition of the racemic compound or that of the resolving agent $\left(\mathrm{ee}_{\mathrm{Dia}} \sim \mathrm{ee}_{\mathrm{EuRac}}\right.$ or $\left.\mathrm{ee}_{\mathrm{Dia}} \sim \mathrm{ee}_{\mathrm{EuRes}}\right)$. However, in course of a given resolution the determinant eutectic composition (of the racemic compound or resolving agent) can be influenced by the solvent and the crystallization time $[13,14]$.

It was comprehensible that the eutectic composition of the racemic compound is determinant $\left(\mathrm{ee}_{\mathrm{EuRac}} \sim \mathrm{ee}_{\mathrm{Dia}}\right)$, as both enantiomers are present. But why can be determinant the resolving agent's code $\left(\mathrm{ee}_{\text {EuRes }} \sim \mathrm{ee}_{\mathrm{Dia}}\right)$ ? The single enantiomer resolving agent is homochiral, thus it has to react in two ways and should incorporate the two enantiomers of the racemic compound into the diastereomeric salt in proportion according to its own memory, vindicating its eutectic composition ( $\left(\mathrm{e}_{\mathrm{EuRes}}\right)$. The $\mathrm{ee}_{\mathrm{Eu}}$ is not the common property of the two enantiomers, but of each separately. Their mirror-image helicity, the ratio of the $\mathrm{P}$ and $\mathrm{M}$ helical supramolecular associates of the resolving agent has to determine the reaction of the single enantiomer resolving agent with the enantiomers of the racemic compound. In our opinion this $\mathrm{ee}_{\mathrm{Dia}} \sim \mathrm{ee}_{\mathrm{EuRes}}$ result can only be formed this way.

In case of benzothiazepine derivatives, the crystalline structures of the two racemic compounds of diastereomeric relation are different, but the enantiomers are present in mirror-image conformations. The enantiomers, however, are participating in the formation of the crystals received from the pure enantiomers with two different conformers, mimicking the racemic structure $[15,16]$.

In the case of the crystallization of Threonine from water, macroscopically visible crystals of mirror-image $\mathrm{P}$ and $\mathrm{M}$ helicity can be separated, crystallized from the $\mathrm{P}$ and $\mathrm{M}$ helicity supramolecular molecule-associates formed previously in the solution [17]. After the separation of the two mirror-image crystals, the enantiomer ratio of the isolated enantiomers was $85: 15$ in both helical structures, thus the ratio of the two different conformers $(\mathrm{P} / \mathrm{M}, \mathrm{M} / \mathrm{P})$ proved to be identical (Figure 6).

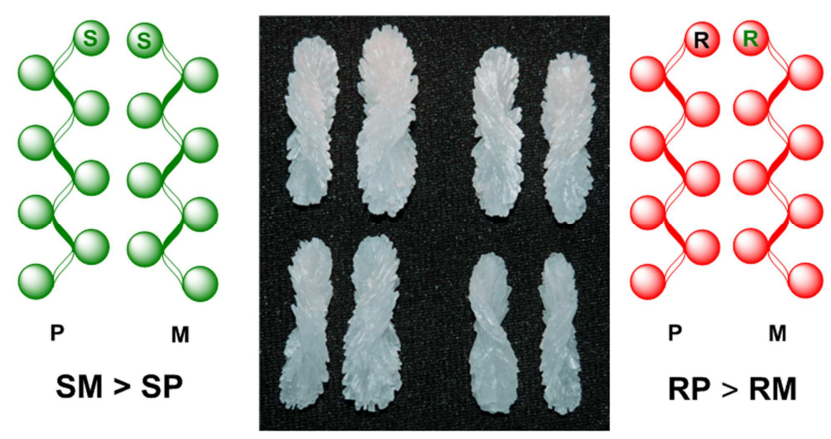

Figure 6. Macroscopically visible crystals appearing in course of the crystallization of Threonine.

These examples underline, that the resolving agents with their conformers of homochiral supramolecular enantiomer associates, also with the enantiomer conformers formed in racemic compounds, form two different $\mathrm{M}$ and $\mathrm{P}$ helicity supramolecular associates, and thus in case of appropriate circumstances the $\mathrm{ee}_{\mathrm{Dia}} \sim \mathrm{ee}_{\text {EuRes }}$ correlation can be observed (Figure 7). 
$x R P+(1-x) R M+x S P+(1-x) S M+2\left[y R^{*}+(1-y) R^{*}\right]$

$\begin{array}{ccc}\underset{\begin{array}{c}\text { the contact time } \\ \text { of phases }\end{array}}{\rightleftharpoons \mathrm{RR}^{*}+\mathrm{SR}^{*}} & \mathrm{Dia}_{1} \mathrm{Dia}_{2}\end{array}$

Dia1 $=$ eeEuRac or eeEuRes

Dia2 $=$ eeEuRes or eeEuRac

Figure 7. A general scheme of the formation of diastereomers.

For example, where " $\mathrm{x}$ " represents the racemic compound, " $\mathrm{y}$ " is the ratio of the $\mathrm{P}$ helicity fraction of the resolving agent. The memory of these chiral molecules is characterized by the fact that the given chiral molecules form the ratio of $\mathrm{P}$ and $\mathrm{M}$ helicity of the supramolecular helical associates by their self-organization.

Based on these observations, a possible mechanism of the diastereomer formation and the reaction of the racemic compound and the resolving agent are shown on Figure 8.
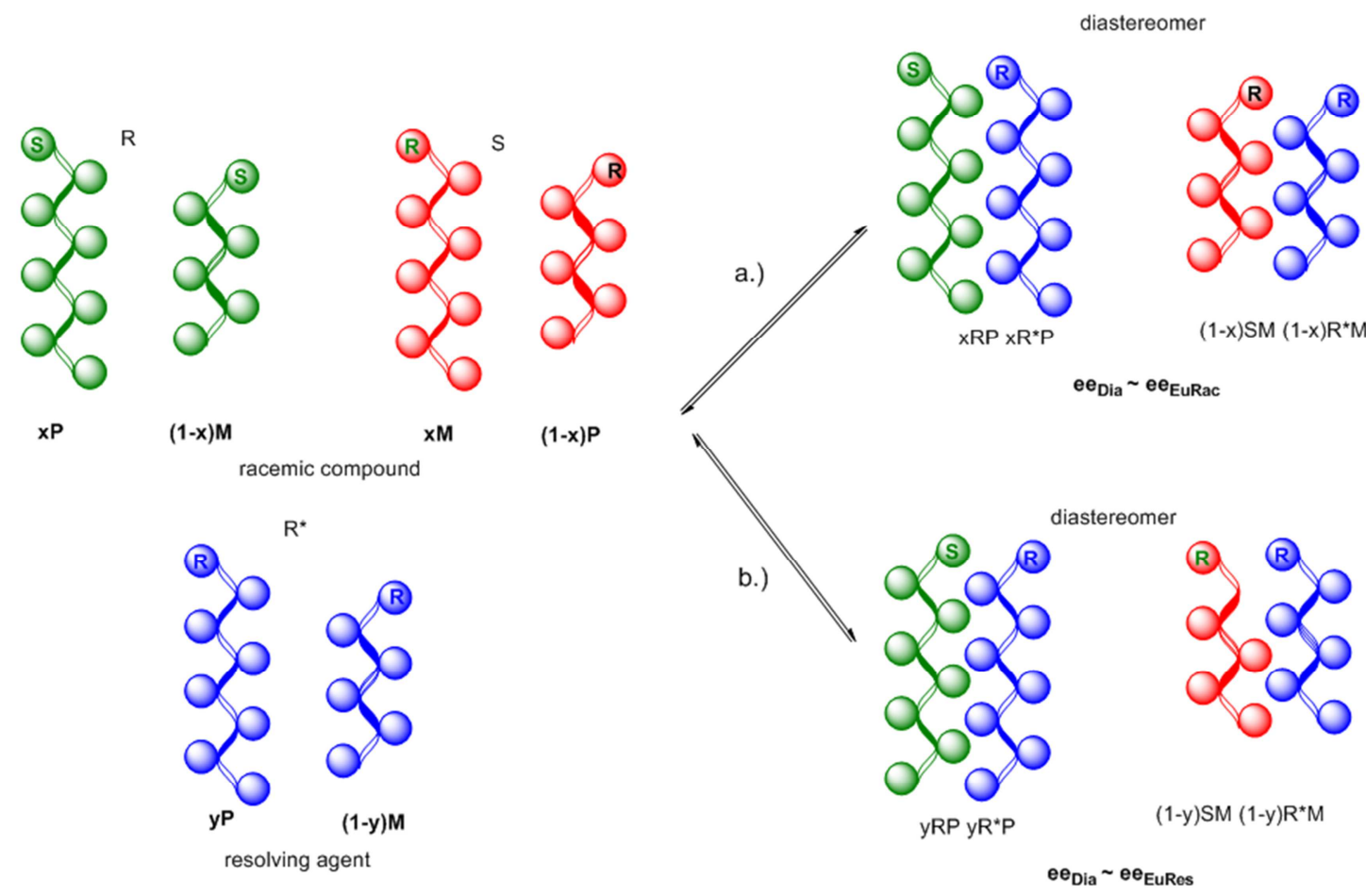

Figure 8. A possible mechanism for the diastereomer formation: a.) if the racemic compound is decisive and b.) the resolving agent is determinat.

The associates of similar helicity can react with each other in the ratio of " $x$ " or " $y$ ", thus forming a new, double-helix associated diastereomeric relation; which, according to their solubility, are distributed between solid and liquid phases. The distribution of the possible diastereomers is determined by the contact time between the two phases (kinetic or thermodynamic control).

Based on the above-mentioned findings, it can be concluded that the single enantiomer resolving agent remembers the conformer ratio of the racemic resolving agent, forming the ratio of the $\mathrm{P}$ and $\mathrm{M}$ helicity structures in the reaction mixture of the resolution. The single enantiomer resolving agent reacts with the enantiomers of the present racemic compound in the way that the enantiomers of the racemic compound take part in the crystallizing diastereomer according to the appropriate ratio of the enantiomer mixtures of the resolving agent (eutectic composition). Consequently, the composition of the diastereomer is determined by the eutectic composition of the resolving agent, based on the memory of the single enantiomer resolving agent $\left(\mathrm{ee}_{\mathrm{Dia}} \sim\right.$ ee EuRes $)$.

If the diastereomer is composed by the ratio of $\mathrm{M}$ and $\mathrm{P}$ conformers of the enantiomers of the racemic compound, the ratio of the enantiomers of the racemic compound in the diastereomer equals to its eutectic composition $\left(\mathrm{ee}_{\mathrm{Dia}} \sim\right.$ ee $\mathrm{EuRac})$.

The calculated $\mathrm{ee}_{\mathrm{Dia}} \sim \mathrm{ee}_{\mathrm{EuRes}}$ and $\mathrm{ee}_{\mathrm{Dia}} \sim \mathrm{ee}_{\mathrm{EuRac}}$ correlations were experimentally confirmed by the data of the resolutions elaborated by us.

In the followings, two resolutions confirming the memory of the resolving agent are presented. In the first one, the resolving agent determines the kinetic control (Figure 9), while in the second case the thermodynamic control (Figure $10)$, vindicating the eutectic composition of the enantiomeric mixtures [18]. 


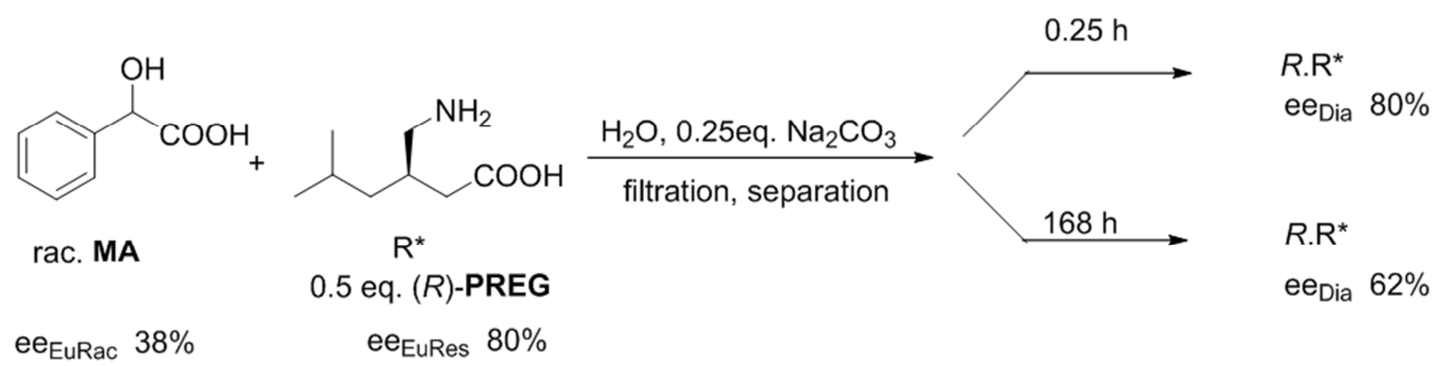

Figure 9. The kinetic control is determined by the resolving agent.

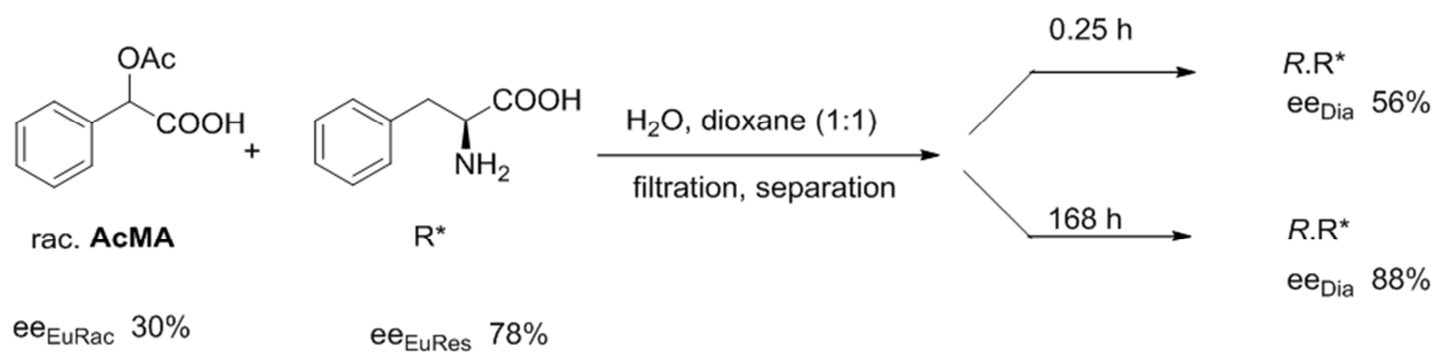

Figure 10. The thermodynamic control is determined by the resolving agent.

We believe, that the code of the chiral-chiral interactions applies, depending on the circumstances, according to the eutectic composition of the most convenient chiral molecule, which eutectic composition can be vindicated even by the ratio of the $\mathrm{M}$ and $\mathrm{P}$ helicity supramolecular associates of the single enantiomer resolving agent.

Consequently, the single enantiomer molecule bears memory in its structure and associates such code, which can determine (in appropriate circumstances) all kinds of chiralchiral reactions.

Supramolecular double-helices can also be formed from achiral molecules, resulting in macroscopically visible crystals of mirror-image relation with each other [16, 19, 20].

The $\mathrm{P}$ and $\mathrm{M}$ supramolecular structures can surely be assumed in the solution of chiral compounds, which form double helices similarly to the ammonium sodium tartrate (TA.NA. $\mathrm{NH}_{4}$ ). Our assumption is that in the solution of single enantiomers the ratio of the supramolecular structures (e.g. P), according to their configuration will be higher than the other one (in this case $\mathrm{M}$ ), and this ratio ensures the code of the given chiral molecule $\left(\mathrm{ee}_{\mathrm{Eu}} \mathrm{s}\right)$.

In case of conglomerate-forming enantiomeric mixtures, one of the enantiomers can mainly be P helicity, while the other enantiomer is $\mathrm{M}$ heltcity.

The formation of supramolecular helical structures is controlled by the self-disproportionation (SDE) of chiral molecules [21-27].

Presumably, the formation of the current structure and $\mathrm{P}>\mathrm{M}$ ratio of the DNA started with the code of the single enantiomer D-ribose. Most likely the ratio of the conformers in D-ribose (or one of its derivatives) was the code (ee $\left.e_{\mathrm{Eu}}\right)$, which started complex "snowball" processes, which started and determined life as we know it.

\section{Conclusion}

During the resolution processes the enantiomers tend to form a stable, more symmetrical conformation, according to their own code. In the interactions they tend to reproduce themselves enforcing their own code. While the selfreproduction of racemic compounds is encoded by its eutectic composition, the resolving agent pursues to reproduce itself from the enantiomers of racemic compound but in the ratio of its eutectic composition, its stochiometry.

Like the DNA in the living organisms reproduces itself and catalyse the processes, according to its own code, by forming supramolecular associates having double helical structure, in the resolution processes the enantiomeric mixtures tend to reproduce themselves forming helical structured supramolecular associates and so catalysing the resolution processes.

\section{Acknowledgements}

The authors thank the financial support of the Hungarian OTKA Fundation (K 124180) for E. Fogassy).

\section{References}

[1] Toth, G., Fogassy, E., Acs, M., Toke, L., Láng, T. Racematspaltung von ( \pm )-5-äthyl-1-(3,4-dimethoxyphenyl)6,7-dimethoxy-4-methyl-5H-2,3-benzodiazepin und anomales chiroptisches verhalten der enantiomeren. J. Heterocycl. Chem. 20 (3), 709-713 (1983).

[2] Bosits, M. Resolution of Grandaxin by diastereomeric salt formation and investigation of purification methods of its enantiomeric. Thesis University of Technology and Economics, Budapest (2016). 
[3] Jacques J, Wilen S. H, Collet A, Enantiomers, racemates and resolution. Wiley-Interf. NY (1881).

[4] Roozeboom H. W. B.: Löslichkeit und Schmelzpunkt als Kriterien für racemische Verbindungen, pseudoracemische Mischkrystalle und inaktive Konglomerate. Z. Phys. Chem. 28, 494 (1899).

[5] Girard, C., Kagan, H. B. Nonlinear Effects in Asymmetric Synthesis and Stereoselective Reactions: Ten Years of Investigation. Angew. Chem. Int. Ed. 37, 2922-2359 (1998).

[6] Brunel, J. M., Lukas, T. O., Kagan, H. B. Nonlinear effects as 'indicators' in the tuning of asymmetric catalysts. Tetrah.: Asymmetry 9, 1941-1946 (1998).

[7] Klussmann, M., Iwamura, H., Mathew, S. P., Wells, D. H., Pandya, U., Armstrong, A., Blackmond, D. G. Thermodynamic control of asymmetric amplification in amino acid catalysis. Nature 441, 621-623 (2006).

[8] Kellog, R. M. The crystallization behavior of proline and its role in asymmetric organocatalysis. Angew. Chem. 46, 494497 (2007).

[9] Balint J, Egri G, Kiss V, Gajary A, Juvancz Z, Fogassy E. Unusual phenomena during the resolution of 6-fluoro-2methyl-1,2,3,4-tetrahydroquinoline (FTHQ): thermodynamickinetic control. Tetrah.: Asymmetry 12, 3435-3439 (2002).

[10] Pálovics, E., Schindler, J., Faigl, F., Fogassy, E. Physical separations: behavior of structurally similar molecules in the resolution processes. In Comprehensive Chirality, Carreira, E., Yamamoto, H., Eds., Vol. 8, pp 91-95 ISBN (print): 978-0-08095167-6. (Elsevier Ltd., Oxford, 2012).

[11] Pálovics, E., Faigl, F., Fogassy, E. Separation of the Mixtures of Chiral Compounds by Crystallization. In Advances in Crystallization Processes, Mastai, Y., Ed., InTech, pp 1-37. ISBN 978-953-51-0581-7 (Rijeka, 2012).

[12] Szeleczky Zs., Semsey S., Bagi P., Pálovics E., Faigl F., Fogassy E. Selecting resolving agents in respect of their eutectic compositions. Chirality: the Pharmacological Biological and Chemical Consequences of Molecular Asymmetry 28(3), 230-234, (2016).

[13] Pálovics, E., Szeleczky, Zs., Fődi, B., Faigl, F., Fogassy, E. Prediction of the efficiency of diastereoisomer separation on the basis of the behaviour of enantiomeric mixtures. RSC Advances 4, 21254-21261 (2014).

[14] Pálovics, E., Szeleczky, Zs., Fogassy, E. Influence of helical structured supramolecular associates and that of eutectic composition on the distribution of enantiomeric and diastereomeric mixtures between phases. Chem. Bull. POLITEHNICA'Univ. (Timisoara) 61(75), 40-43 (2016).

[15] Marthi, K., Larsen, S., Ács, M., Jászay, Zs., Fogassy, E. Enantiomer associations in the crystal structures of racemic and (2S, 3R)-(-)-3-hydroxy-2-(4-methoxyphenyl)-2,3dihydro-1,5-benzothiazepin-4(5H)-one. Acta. Chem. Scand.
50, 906-913 (1996).

[16] Marthi, K., Larsen, S., Ács, M., Fogassy, E. Enantiomer assosiations in the crystal structures of racemic and $(2 \mathrm{~S}, 3 \mathrm{~S})-$ (+)-3-hydroxy-2-(4-methoxyphenyl)-2,3-dihydro-1,5benzothiazepin-4(5H)-one. J. M. Struct. 374, 347-355 (1996)

[17] Viedma C., McBride J. M., Kahr B., Cintas P. Enantiomerspecific oriented attachment: formation of macroscopic homochiral crystal aggregates from a racemic system. Angew. Chem. Int. Ed. $52 \mathrm{~m}$ 10541-10545 (2013).

[18] Szeleczky Zs., Bagi P., Pálovics E., Fogassy E. The effect of the eutectic composition on the outcome of kinetically and thermodinamically controlled resolutios that are based on the formation of diastereomers. Tetrah.: Asymmetry 26, 377-384, (2015).

[19] Koshima, H., Matsuura, T. Chiral crystallization of achiral organic compounds - generation of chirality without chiral environment. J. Synth. Org. Chem. 56, 268H. (1998).

[20] Kahr, B., Shtukenberg, A., Gunn, A., Carter, J. D., Rohl, L. A. Controlling mesoscale crystal helicity with additives, again Cryst. Grown and Design 11, 2070-2073 (2011).

[21] Soloshonok, V. A. Remarkable amplification of the selfdisproportionation of enantiomers on achiral-phase chromatography columns. Angew. Chem. Int. Ed. 45, 766-769 (2006).

[22] Pavlov, V., Pavlova, T. N. Paradoxes of symmetry: homochirality, cryptochiral reactions, chiral field, memory, and induction, chiral and racemic environment. Curr. Org. Chem. 21, 872-888 (2017).

[23] Oaki, Y., Imai, H. Stereospecific morphogenesis of aspartic acid helical crystals through molecular recognition. Langmuir 23, 5466-5470 (2007).

[24] Kobayashi, Y., Kodama, K., Saigo, K. Supramolecular architecture consisting of an enantiopure amine and an achiral carboxylic acid: application to the enantioseparation of racemic alcohols. Org Lett. 6, (17), 2941-2944 (2004).

[25] Kobayashi, Y., Kodama, K., Saigo,K. Enantioselective inclusion of chiral alkyl aryl sulfoxides in a supramolecular helical channel consisting of an enantiopure 1,2-amino alcohol and an achiral carboxylic acid. Tetrah.: Asymmetry 19, 295301 (2008).

[26] Weissbuch, I., Leiserowitz, L., Lahav, M. Stochastic "mirror symmetry breaking" via self-assembly reactivity and amplification of chirality: relevance to abiotic conditions. Top. Curr. Chem. 259, 123-165 (2005).

[27] Tamura, R., Iwama, S., Gonnade, R. G. Control of polymorphic transition inducing preferential enrichment. Cryst. Eng. Comm, 13, 5269-5280 (2011). 